\title{
O CASAMENTO E O DEVER DE COABITAÇÃO NO CÓDIGO DE HAMMURABI, NO PENTATEUCO E NA LEI DE MANU
}

\author{
Antonio Cláudio da Costa Machado \\ Professor Assistente do Departamento de Direito Processual da FDUSP
}

Resumo:

Textos legais que integram as antigas legislações babilônica, judaica e hindu revelam as possíveis origens de alguns comportamentos concernentes ao dever de coabitação e de fidelidade incorporados na disciplina do casamento romano.

Abstract:

Legal texts that make whole of the ancient babylonian, jewish and hindu legislation reveal the possible origin of some kinds of behavior concerning to the cohabitation and faithfulness duty incorporated in the roman marriage discipline.

Unitermos: Coabitação, fidelidade, divórcio.

1. $\mathrm{O}$ objeto deste pequeno trabalho é o estudo comparado do dever de coabitação e de fidelidade e suas conseqüências na legislação de três grandes civilizações da Antigüidade: a babilônica, a judaica e a hindu. $O$ intuito específico é o de buscar possíveis origens de práticas incorporadas nos institutos do repúdio e divórcio romanos.

2. Dissertando a respeito do dever de coabitação, ensina Álvaro Villaça Azevedo que o casamento romano "surgia sem necessidade de forma jurídica" e que no seu bojo se incluía o dever coabitacional. Citando Charles Mayns, conclui o mestre que a lei romana encarava tal dever no plano ético "muito embora tenha, em algumas disposições de caráter positivo, acolhido essas relações morais como na imposição do dever de fidelidade. (Dever de Coabitação Inadimplemento, São Paulo, Bushatsky, 1976, capítulo II, p. 58).

Antes de enfrentarmos o dever em questão, uma palavra sobre a constituição do casamento no direito comparado.

Se, em Roma, o casamento nascia independentemente de forma jurídica, 
na Babilônia, para a constituição do vínculo matrimonial, era necessária uma formalidade essencial, o contrato escrito, de acordo com o $\S 128$ do Código de Hammurabi que remonta ao século XVII a.C. Os romanos, extremamente práticos em suas soluções, jamais se submeteriam a formalidades que não tiveram aceitação anterior e que sempre se revelaram desnecessárias para a segurança do casamento. $\mathrm{O}$ Pentateuco surgido no século XV a.C. não previa qualquer forma, bastando o relacionamento sexual para a sua consumação. Nenhuma formalidade estrita, identicamente, era exigida pelas Leis de Manu, compiladas na Índia no século V a.C.; apenas a união das mãos dos esposos era parte essencial da cerimônia de casamento, chamado, por isso, panigraha (Leis de Manu, Santiago do Chile, Ercilla, 1941, nota 1, p. 40).

3. Especificamente no que concerne ao dever de fidelidade, expressão do dever de coabitação, observa o professor Álvaro Villaça Azevedo, apoiado agora por Max Kaser, que 'a fidelidade conjugal só foi obrigatória ao marido na era cristã, tendo sempre, obrigado exclusivamente a mulher" concluindo, em seguida, que "ante a quase nenhuma proteção à mulher, fica difícil, para não dizer impossível, a consideração das relações entre os cônjuges", cujos preceitos reguladores pertenciam à ordem ética (ob. cit., p. 59). Seja como for, embora não propriamente jurídico, mas ético, o dever de fidelidade existia pelo menos em relação à mulher, e seu descumprimento sempre gerou penalizações severas, de sorte que parece relevante traçar o paralelo entre as grandes legislações anteriores à romana no que concerne ao tema.

$\mathrm{Na}$ Babilônia, o sistema familiar era nitidamente patriarcal. Cabia ao pai, dentro do seu vasto poder, por exemplo: vender a esposa e os filhos em virtude de dívida, embora por quatro anos somente ( $\$ 117$ ); casar-se com mais de uma mulher ( $\S \S$ 145 a 148), embora, em geral, o casamento fosse monogâmico, segundo observação de Emmanuel Bouzon (O Código de Hammurabi, Petrópolis, $4^{\text {a }}$ ed., Vozes, 1987, p. 36); repudiar sua mulher, apesar das restrições impostas ( $\$ \$ 138$ a 141) e; ver sua mulher morta por afogamento, caso esta praticasse adultério ( $\$ 129,130$ e 133). Todo este contexto jurídico mostra claramente que só da mulher se exigia fidelidade e não do marido (faremos referência às exceções mais à frente).

Também entre os judeus, segundo o Pentateuco, pelo menos no princípio, o marido possuía dentre outros: o poder de vida e morte sobre mulher e filhos; poder sexual sobre suas escravas; a faculdade de casar com quantas mulheres desejasse (Ex. 21:9 a 10; Dt. 21:15 a 17; Gn. 21 e 29; I Reis 11); o direito de repudiar sua esposa (Dt. 24: 1 a 4) e, identicamente, de assistir seu apedrejamento em caso de 
adultério (Ex. 20: 10 e 18; Lv. 18:20; Dt. 5:21). Tal disciplina revela, também, que a fidelidade era dever imposto exclusivamente à mulher.

Já no que concerne à civilização hindu, dada a enorme consideração de que era merecedora a mulher ("onde se honram as mulheres, estão satisfeitas as Divindades; mas quando não são honradas, são estéreis todos os atos piedosos": v. 56, L. III), como consequiência, o casamento criava para os dois cônjuges o dever de fidelidade ("que a mútua fidelidade se mantenha até a morte, tal é, em suma,o principal dever da mulher e do marido": v. 101, L. IX). Assim, embora no direito hindu o marido exercesse grande poder sobre a esposa (v. 148, L. V; 5 a 7, 10, 12 e 46, L. IX) e esta, por sua vez, devesse a ele respeito "como a um deus" (v. 151 e 154, L. $\mathrm{V}$ ), a infidelidade do marido também era considerada extremamente grave sob o ponto de vista moral, espiritual e jurídico (v. 48 a 52, 102, L. IX; 170, 178, L. X; 60, L. XI) mesmo que em certas classes fosse admitida a poligamia (v. g., v. 149 e 183, L. IX) e o divórcio reconhecido (v. 77 a 82, L. IX).

Do exposto, o que fica claro é que em termos do dever de fidelidade a postura legal romana mais se aproximava da babilônia e da judaica do que da hindu, o que se explica pelo fato das duas primeiras culturas terem exercido bem maior influência sobre os povos na Antigüidade, uma vez que a Mesopotâmia e a Palestina se encontravam no centro do mundo civilizado da época. Osvaldo Flávio Degragia assevera que as Leis de Manu "influíram quase que exclusivamente na Índia, sem a penetração do Código de Hammurabi que se infiltrou na Síria, Judéia e Grécia", concluindo, com citação de Jaime Altavila, que a lei babilônica "representou um legado comparado ao que Roma fez ao mundo moderno" (O Poder Judiciário através dos tempos, Porto Alegre, Livr. Sulina, 1968, p. 20).

4.

Após reiterar a conclusão de que o dever de coabitação existiu no Direito Romano, passa o professor Álvaro Villaça Azevedo a elencar várias causas de dissolução do matrimônio mencionadas por Paulo: o divórcio, a morte, o cativeiro, ou por outra eventual servidão de qualquer dos cônjuges.

A partir deste paradigma, vejamos como os eventos referidos foram enfocados no direito anterior ao romano.

5. Quanto à morte, não há dúvida de que tanto no direito babilônico como no judaico este fato gerava a dissolução do casamento, permitindo à mulher casar-se outra vez. Entre os judeus, contudo, se o marido morresse sem deixar filhos, o 
casamento subsequiente da viúva deveria ser com seu cunhado (o irmão do marido) para suscitar descendência ao morto: o levirato (Dt. 25: 5 a 10). Já no que concerne ao direito hindu é interessante observar que as Leis de Manu não autorizavam o casamento da viúva: o v. 156, L. V, afirma que "uma mulher virtuosa ... não deve fazer nada que possa desagradá-lo (o marido), seja durante a vida, seja depois de sua morte"; no v. 157 encontramos que "... depois de ter perdido seu marido, não pronuncie (a mulher) sequer o nome de outro homem"; e no v. 158 "que até a morte se conserve paciente $e$ resignada, entregue a práticas piedosas, casta e sóbria", observando a "conduta das mulheres que não têm senão um só esposo"

6. No que diz respeito ao cativeiro - que no Direito Romano tinha a qualificação de capitis diminutio máxima, só desaparecendo com a post liminium, sem, contudo, restaurar o casamento - bastante curioso é o seu tratamento no Código de Hammurabi.

$\mathrm{Na}$ Babilônia, a conseqüência jurídica do cativeiro dependia de fundamentalmente uma circunstância, qual seja, a existência ou não de alimentos na casa do cativo: se houvesse o que comer em sua casa, a mulher do cativo não poderia entrar na casa de outro homem. "Se essa mulher não cuidou de si e entrou na casa de um outro, comprovarão (isto) contra essa mulher e lançarão n' água" (§ 133); se não houvesse o que comer, a mulher do cativo "poderá entrar na casa de um outro. Essa mulher não tem culpa" ( $\$ 134)$; no caso de volta do cativo, este recuperaria a esposa, mas os filhos da segunda união "seguirão o pai" (§ 135). No Pentateuco, não havia disciplina para a hipótese do judeu que se tornasse cativo em mão de estrangeiro, mas apenas para a situação do judeu que se tornasse escravo de outro judeu (seria liberto no sétimo ano: Dt. 15:12) ou, ainda, para os escravos de outras nações (Ex. 21:3; L.V 25:44 a 46). Existe, no entanto, na Lei de Moisés, uma regra cujo conteúdo se assemelha à solução romana numa hipótese: se o homem era casado quando se tornou escravo, "com sua mulher" sairia (Ex. 21:3), o que faz supor que a escravidão também alcançava a mulher e no seu curso o casamento era mantido. No Direito Romano, "se os esposos fossem feitos prisioneiros, ficando no mesmo cativeiro, de tal sorte que não se interrompesse a coabitação, voltando a Roma, pelo 'post liminium' seu casamento era considerado válido" (Álvaro Villaça Azevedo, ob. cit., p. 63).

Ainda quanto ao cativeiro, observa Álvaro Villaça Azevedo que em Roma "interrompida a vida em comum, não se podia falar em casamento, mesmo que existisse intenção de mantê-lo" concluindo, então, pouco mais a frente que "o 
inadimplemento do dever de coabitação é causa de rompimento do vínculo conjugal, sem que exista culpa por parte do inadimplente cativo" (ob. cit., p. 64). Como se vê pelo estudo comparado, na Babilônia já havia a idéia de rompimento do matrimônio pela só interrupção da vida em comum, mas esta dependia de um elemento objetivo adicional: a falta de provisão na casa do cativo.

7.

Acerca do divórcio, que sempre foi admitido entre os romanos, duas figuras precisam ser separadas: o repúdio e o divórcio propriamente dito. Como afirmam Alexandre Correia-Gaetano Sciascia "quando a dissolução deriva da vontade de um dos cônjuges, temos o 'repudium'; quando a vontade é bilateral, se dá o 'divortium"' (Manual de Direito Romano, São Paulo, Saraiva, 1953, v. I, p. 127). Deixando de lado qualquer consideração sobre as espécies de casamento romano (cum manu e sine manu), cuja repercussão a nível do tema proposto, em princípio, é apenas formal (Correia-Sciascia, ob. cit., p. 127-8), examinemos as modalidades de divórcio, estas sim importantes para o nosso estudo. Ensinam Alexandre Correia-Gaetano Sciascia que 'Justiniano distinguia (a) 'divortium ex iusta causa', que é um repúdio em casos determinados pela lei, implicando graves sanções a cargo do culpado; (b) 'divortium sine causa', punido mas válido; (c) 'divortium bona gratia', que é determinado pelo voto de castidade de um dos cônjuges e não acarreta nenhuma sanção" (ob. cit., p. 128).

Segundo lição de Álvaro Villaça Azevedo, o divórcio com justa causa (unilateral ou, simplesmente, repúdio), legítimo apenas quando se fundasse nas causas estabelecidas na Novela 117, capítulos VIII e IX, podia ser pedido pelo marido nas hipóteses que seguem: a) adultério; b) comportamento leviano da esposa pela freqüência "com estranhos, e sem autorização do marido" a "banquetes, banhos, espetáculos públicos"; c) "falar a mulher, fora do seu lar, com quem não fosse seu parente"; d) recusa da mulher de residir na habitação conjugal. Já a mulher podia pedir o divórcio se: e) o marido tentasse prostituí-la; f) "abandonasse o domicílio conjugal"; g) ou "mantivesse concubina dentro ou fora do mesmo" (ob. cit., p. 169). Vejamos tais situações no direito comparado.

7.1.1 Sobre o adultério (a), já dissemos no item 3 retro que este sempre foi motivo de severas penalidades impostas à mulher: afogamento entre os babilônicos e apedrejamento entre os judeus. Contudo, este fato também gerava comumente o simples repúdio pelo marido tanto perante o Código de Hammurabi (§§ 138 e 142), 
onde era ainda previsto o perdão (§ 129), como perante a Lei de Moisés (Dt. 24:1).

7.1.2 O "comportamento leviano da esposa" (b) também era motivo para o repúdio antes do Direito Romano. O Código de Hammurabi, no $§ 143$, prevê uma hipótese de pena de morte da mulher que certamente gerava em muitas circunstâncias o mero repúdio: "Se ela não se guarda, mas é saidora, dilapida sua casa e despreza seu marido, lançarão essa mulher n' água" A generalidade do "não se guarda" ou do "despreza seu marido" autorizam a inferência. Entre os judeus, a interpretação rabínica liberal de Deuteronômio 24:1 também incluía o "comportamento leviano da esposa", segundo Henry Daniel-Rops (A vida diária nos tempos de Jesus, São Paulo, Vida Nova, 1986, p. 92). Identicamente, no Direito da Índia, entre os hindus atos desta natureza são mencionados como o recebimento de flores e perfumes, o assentar-se num leito com um homem ou o toque do seus adornos e vestidos, fatos que a lei presumia como "amor adúltero" (v. 357, L. VIII).

7.1.3 O "falar fora do lar com quem não fosse seu parente" (c) é expressamente previsto nas Leis de Manu: genericamente (v. 354 e 355); especificamente na hipótese da conversa acontecer em local de peregrinação, bosque ou na confluência de rios quando era considerada adultério (v. 356, L. VIII). Esta situação autorizava o repúdio entre os judeus com base na mesma interpretação liberal de Deuteronômio 24:1 (Henry Daniel-Rops, ob. cit., p. 88).

7.1.4 Quanto à recusa de habitação no lar conjugal (d), é expresso o Código de Hammurabi: "Se essa mulher não concordou em morar na casa de seu marido, ele lhe restituirá, integralmente, o dote que ela trouxe da casa de seu pai e ela irá embora" ( $\$$ 149). Entre os judeus a mesma interpretação liberal já algumas vezes referida incluía a hipótese. O v. 149, L. V, das Leis de Manu, fala que a mulher não deve se separar de seu pai, de seu esposo e de seus filhos, posto que deles depende (v. 148).

7.1.5 Já quanto às hipóteses de repúdio pela mulher, temos a dizer o que segue. A tentativa de prostituição (e) não é prevista especificamente em nenhuma das três legislações examinadas como fato autorizador do divórcio. Em Israel se o fato acontecesse, a solução seria a mulher reclamar aos anciãos (juízes da comunidade) e estes provocariam o marido a repudiar, já que a mulher não era titular de tal direito. $\mathrm{Na}$ Babilônia talvez a hipótese pudesse ser enquadrada neste avançadíssimo dispositivo do Código de Hammurabi: "Se uma mulher tomou aversão a seu esposo e disse-lhe: 'Tu 
não terás relações comigo', seu caso será examinado em seu distrito. Se ela se guarda e não tem falta e o seu marido é um saidor e a despreza muito, essa mulher não tem culpa, ela tomará seu dote e irá para a casa do seu pai" O termo "desprezamento" dada a sua largueza de significado, podia comportar, destarte, a tentativa de prostituição.

7.1.6 $\mathrm{O}$ "abandono do domicílio conjugal" pelo marido (f) não é mencionado em nenhum texto legislativo. A única solução em que se pode pensar, talvez seja a apontada para a situação "e" acima. E, finalmente, a "manutenção de concubina dentro ou fora do lar" (g) não é da mesma maneira objeto de qualquer prescrição, mesmo porque a poligamia era reconhecida e disciplinada tanto em Israel quanto na Babilônia.

7.2 O divórcio sem justa causa dos romanos, como vimos, era aquele que ocorria sem amparo dos motivos elencados expressamente pela lei e que, por isso, gerava severas penas para o repudiador.

É importante observar, nesse passo, que o Código de Hammurabi, muito antes, já restringia o abuso no exercício do direito marital de repudiar, como se vê exemplificativamente nos seguintes textos: "§ 138. Se um awilum quer abandonar sua primeira esposa, que não lhe gerou filhos, dar-lhe-á prata correspondente à sua 'terhatum' e restituir-lhe-á o dote que trouxe da casa de seu pai; (então) poderá abandoná-la" Grandes restrições eram impostas, outrossim, no caso de abandono de sacerdotisas como se percebe pela redação do $§ 137$ : além da devolução do dote, a sacerdotisa tinha direito à "metade do campo, do pomar e dos bens móveis e ela educará os seus filhos, dar-lhe-ão a parte correspondente à de um herdeiro e o marido do seu coração poderá desposá-la" No, direito hebraico, divórcio com penalidades não existia; o que havia era a proibição pura e simples em determinados casos.

7.3 Como bem nos lembra Álvaro Villaça Azevedo, o divortium bona gratia, bilateral ou unilateral, "existia diante de situações que impossibilitavam a continuidade dos fins matrimoniais sem que qualquer dos cônjuges fosse culpado, como o voto de castidade, a impotência incurável, a esterilidade, e o cativeiro, sem que se tenha notícias do aprisionado, há mais de cinco anos, segundo a Novela 22, capítulos IV a VII" (ob. cit., p. 69).

Sobre o cativeiro já falamos. Quanto à esterilidade, esta podia gerar entre babilônicos e judeus o repúdio puro e simples (Código de Hammurabi, $\S 138$, v. g.) ou, entre estes últimos, a tomada de uma escrava ou serva ou, ainda, concubina que 
pudesse gerar filhos ao marido. A impotência, por seu turno, não recebeu destas duas legislações qualquer atenção, mas o v. 79 das Leis de Manu fala da hipótese expressamente: "Mas a que tem aversão por um marido insensato ou culpável de grandes crimes, ou eunuco, ou impotente, ou enfermo ... não deve ser abandonada nem privada de seus bens". Quanto ao voto de castidade, sabe-se que este existiu entre os hebreus (celibato) e hindianos, mas nenhuma regra parecia disciplinar o rompimento do matrimônio por tal motivo.

7.4 Embora proibido à princípio por Justiniano, o divortium communi consensu foi reeditado por Justino II, seu sucessor, na Novela 140, observa Álvaro Villaça Azevedo (ob. cit., p. 69). Acerca desta modalidade de divórcio, nenhuma disposição expressa existe nem no Código de Hammurabi, nem no Pentateuco de Moisés, nem nas Leis de Manu.

7.5 Por fim, são de rigor algumas observações comparativas a respeito de duas características do divórcio romano:

- A primeira característica que queremos examinar é a relativa à total desnecessidade de decreto judicial para que se operasse o efeito de romper o vínculo pelo divórcio em Roma, já que se considerava a separação como negócio privado ( $\mathrm{F}$. Mackeldey, apud Álvaro Villaça Azevedo, ob. cit., p. 66). Nem sempre foi assim que o divórcio se aperfeiçoou no direito anterior. No Código de Hammurabi algumas passagens mostram que era necessária a comprovação judicial de determinados fatos para o decreto do divórcio: apropriação indevida de bens, desprezo pelo marido ( $\S$ 141 ); aversão pelo esposo e desprezo pela mulher ( $\$ 1142$ e 143). Talvez fosse sempre necessária a participação do magistrado. Não é possível afirmar.

- A segunda e última característica que merece realce é a concernente a medidas que foram tomadas no período final da República, início do Principado, tendentes a diminuir o número de divórcios, entre os quais são mencionadas a punição do adultério e a retenção do dote (Álvaro Villaça Azevedo, ob. cit., p. 68). A retenção do dote ou perda do dote era figura conhecida tanto dos hebreus quanto dos babilônicos, também como meio de restringir a prática indiscriminada do divórcio.

São Paulo, janeiro de 1996. 